\title{
What Is in Your Beet Juice? Nitrate and Nitrite Content of Beet Juice Products Marketed to Athletes
}

\author{
Edgar J. Gallardo and Andrew R. Coggan \\ Indiana University Purdue University Indianapolis
}

\begin{abstract}
Consumption of beetroot juice (BRJ) supplements has become popular among athletes because beets tend to be rich in nitrate $\left(\mathrm{NO}_{3}{ }^{-}\right)$, which can enhance exercise performance by increasing nitric oxide production. The $\mathrm{NO}_{3}{ }^{-}$content of beets can vary significantly, however, making it difficult to know how much $\mathrm{NO}_{3}{ }^{-}$any product actually contains. Samples from 45 different lots of 24 different BRJ products from 21 different companies were therefore analyzed for $\mathrm{NO}_{3}{ }^{-}$(and nitrite $\left[\mathrm{NO}_{2}{ }^{-}\right]$) concentration using high-performance liquid chromatography. The $\mathrm{NO}_{3}{ }^{-}$and $\mathrm{NO}_{2}{ }^{-}$content (i.e., amount per serving) was then calculated based on either (a) the manufacturer's recommended serving size (for prepackaged/single dose products) or (b) as used in previous studies, a volume of $500 \mathrm{ml}$ (for BRJ sold in bulk containers). There was moderate-to-large variability in $\mathrm{NO}_{3}{ }^{-}$content between samples of the same product, with a mean coefficient of variation of 30\% $\pm 26 \%$ (range 2-83\%). There was even greater variability between products, with a $\sim 50$-fold range in $\mathrm{NO}_{3}{ }^{-}$content between the lowest and highest. Only five products consistently provided $\geq 5 \mathrm{mmol}$ of $\mathrm{NO}_{3}{ }^{-}$/serving, which seems to be the minimal dose required to enhance exercise performance in most individuals. $\mathrm{NO}_{2}{ }^{-}$contents were generally low (i.e., $\leq 0.5 \%$ compared with $\mathrm{NO}_{3}{ }^{-}$), although two products contained $10 \%$ and $14 \%$. The results of this study may be useful to athletes and their support staff contemplating which (if any) BRJ product to utilize. These data may also offer insight into variability in the literature with respect to the effects of BRJ on exercise performance.
\end{abstract}

Keywords: exercise, nitric oxide, supplements

Numerous studies in recent years have investigated the effects of dietary nitrate $\left(\mathrm{NO}_{3}{ }^{-}\right)$on the physiological responses to, and/or performance during, exercise. This interest stems from the fact that dietary $\mathrm{NO}_{3}{ }^{-}$is an important source of nitric oxide (NO) via the "reverse" $\mathrm{NO}_{3}^{-} \rightarrow$ nitrite $\left(\mathrm{NO}_{2}^{-}\right) \rightarrow \mathrm{NO}$ enterosalivary pathway (Kharti et al., 2017). $\mathrm{NO}_{3}{ }^{-}$induced increases in $\mathrm{NO}$ bioavailability have been found to enhance both endurance exercise performance (Jones et al., 2018; Van De Walle \& Vukovich, 2018) as a result of alterations in oxygen supply, demand, and/or cellular energetics (Bailey et al., 2010), and sprint performance (Rimer et al., 2016) as a result of improvements in muscle contractile properties, that is, in maximal muscle speed and power (Coggan et al., 2015b, 2018b). For example, Lansley et al. (2011a) observed a 2.7-2.8\% improvement in mean power during simulated $4-$ and $16.1-\mathrm{km}$ cycling time trials, whereas Rimer et al. (2016) reported a 6.5\% increase in maximal power during an inertial load sprint cycling test. Positive effects of BRJ seem to be most apparent in untrained or moderately trained individuals (Van De Walle \& Vukovich, 2018) or patient groups, (Coggan et al., 2015a, 2018a) and less evident or even absent in highly trained athletes (e.g., Bescós et al., 2012). Notably, however, some studies (Hoon et al., 2015; Oskarsson \& McGawley, 2018) have yielded negative results for reasons that do not seem to be related to differences in subject selection or other aspects of the experimental design.

Most studies of dietary $\mathrm{NO}_{3}{ }^{-}$and exercise have used beetroot juice (BRJ) as a source. This is because beets are relatively rich in

Gallardo and Coggan are with the Dept. of Kinesiology, Indiana University Purdue University Indianapolis, Indianapolis, IN. Coggan is also with the Dept. of Cellular and Integrative Physiology, Indiana University Purdue University Indianapolis, Indianapolis, IN. Address author correspondence to Andrew R. Coggan at acoggan@iupui.edu.
$\mathrm{NO}_{3}^{-}$(Santamaria, 2006) and are readily juiced. Consequently, lay publications frequently contain articles extolling the virtues of BRJ supplementation as an ergogenic aid, and a large number of BRJ supplements in various forms (i.e., powders, mixed drinks, concentrates, bulk juice) are now marketed to athletes. However, the $\mathrm{NO}_{3}{ }^{-}$content of beets or BRJ depends heavily on a number of factors, including the growing conditions, the variety of beet, and the method of preparation (i.e., fresh vs. processed; Corleto et al., 2018; dos Santos Baião et al., 2016; Wruss et al., 2015). Furthermore, most BRJ supplements are not labeled with their $\mathrm{NO}_{3}{ }^{-}$ content, which in any case has only rarely been independently tested. Even some scientific studies have not verified the $\mathrm{NO}_{3}{ }^{-}$ content of the BRJ supplement used and/or measured any biomarkers of $\mathrm{NO}$ bioavailability (e.g., plasma $\mathrm{NO}_{3}{ }^{-}$or $\mathrm{NO}_{2}{ }^{-}$, breath $\mathrm{NO}$ ) to ensure that an adequate dose of $\mathrm{NO}_{3}^{-}$has been provided (e.g., Hoon et al., 2015; Oskarsson \& McGawley, 2018). Athletes and/or their support staff have therefore generally relied on blind faith that any BRJ supplement contains sufficient $\mathrm{NO}_{3}{ }^{-}$to provide physiological benefits.

The purpose of this study was therefore to determine the $\mathrm{NO}_{3}{ }^{-}$ (and $\mathrm{NO}_{2}^{-}$) content of various commercial BRJ supplements. The results may be useful to athletes, coaches, and scientists contemplating which (if any) BRJ product to use and may also offer some insight into factors contributing to variability in the literature with respect to the effects of BRJ on exercise performance.

\section{Methods}

To aid interpretation of the data, we chose to test products that (a) contained BRJ as the primary ingredient, (b) did not contain other ingredients (e.g., L-arginine) intended to alter NO bioavailability, and (c) were marketed toward athletes and/or athletic 
performance or were available from sources readily accessible by athletes. Products were purchased from local grocers, large online retailers, specialized "health food" websites, or directly from the producer. Our initial goal was to obtain samples from three different lots of each product, but in many instances, infrequent production runs limited us to testing just one or two different lots of a given product. We ultimately obtained samples from 45 different lots of 24 different BRJ products (i.e., $n=6$ each of powders, mixed beverages, concentrates, and bulk juice) produced by 21 different companies. All samples were purchased between September 2017 and June 2018, stored for $\leq 2$ weeks at room temperature or under refrigeration as recommended for that product, and tested before the declared expiration date.

Powdered products were first reconstituted by thoroughly mixing one serving, that is, an entire packet or scoop, with $100 \mathrm{ml}$ of $\mathrm{NO}_{3}{ }^{-}$- and $\mathrm{NO}_{2}{ }^{-}$-free, double-distilled water. A small aliquot of each reconstituted powder or original liquid product was then diluted 1,000-fold and the $\mathrm{NO}_{3}{ }^{-}$and $\mathrm{NO}_{2}{ }^{-}$concentration measured by injecting $10 \mu \mathrm{l}$ into a dedicated high-performance liquid chromatography analyzer (ENO-30; Eicom USA, San Diego, CA). This analyzer has previously been described in detail (Coggan et al. 2015a; Troutman et al., 2018). The high-performance liquid chromatography analyzer was calibrated prior to each use by injecting known standards. The $\mathrm{NO}_{3}{ }^{-}$and $\mathrm{NO}_{2}{ }^{-}$content of each product (i.e., $\mathrm{mmol} / \mathrm{serving}$ ) was calculated from these concentration measurements based on either (a) the manufacturer's recommended serving size or (b) for BRJ products sold in bulk containers, a
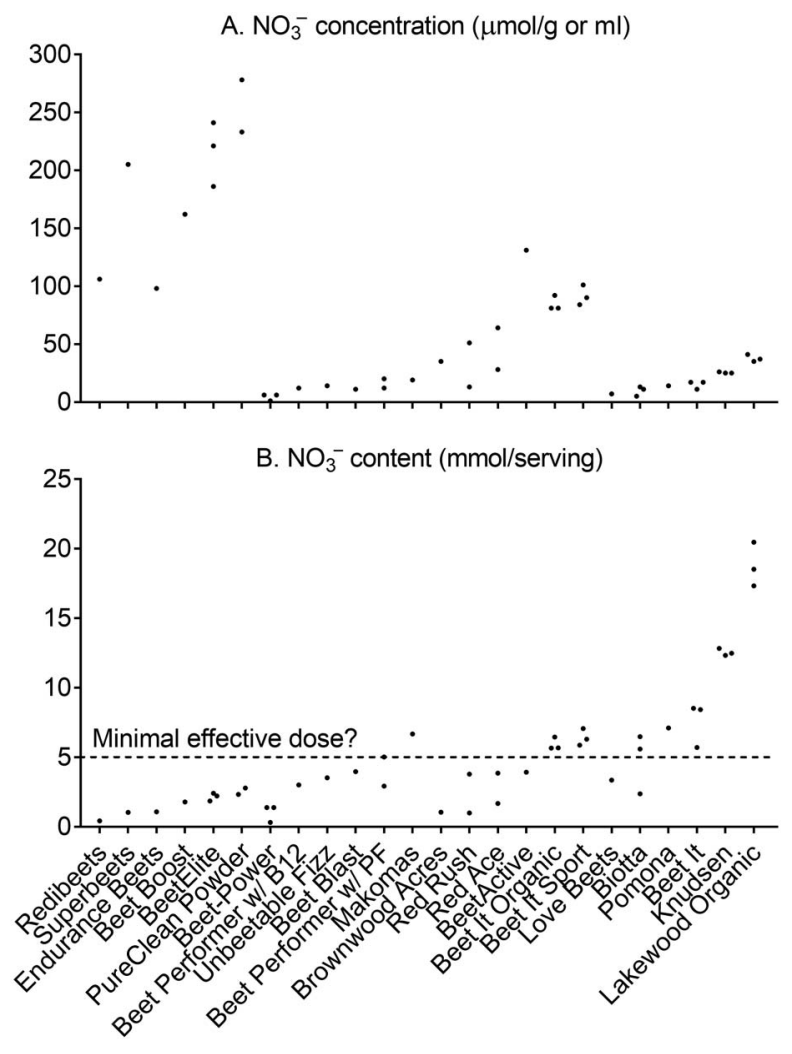

Figure $1-\mathrm{NO}_{3}^{-}$concentration (a) and content (b) of BRJ supplements. Data for each sample tested are shown (circles). In addition, the minimal dose apparently required to increase exercise performance (i.e., $5 \mathrm{mmol}$ ) (dashed line), based on a recent review by Jones et al. (2018), is also shown. $\mathrm{NO}_{3}{ }^{-}=$nitrate; $\mathrm{BRJ}=$ beetroot juice. volume of $500 \mathrm{ml}$ as used in previous studies of BRJ and athletic performance (e.g., Bailey et al., 2010).

Because of the limited number of samples available per product, no attempt was made to compare different products statistically. However, the mean $\mathrm{NO}_{3}{ }^{-}$concentration of different types of BRJ products (i.e., powders vs. mixed beverages vs. concentrates vs. bulk juices) was compared using one-way analysis of variance. A $p<.05$ was considered statistically significant. Statistical analyses were performed using GraphPad Prism (version 7.02; GraphPad Software, La Jolla, CA).

\section{Results}

Data for $\mathrm{NO}_{3}{ }^{-}$and $\mathrm{NO}_{2}{ }^{-}$concentration (i.e., per $\mathrm{g}$ or $\mathrm{ml}$ ) and content (i.e., per recommended serving) for each sample are shown in Figures 1 and 2, whereas average values for content are provided in Table 1. The $\mathrm{NO}_{3}{ }^{-}$concentration of powders (i.e., $174 \pm$ $63 \mu \mathrm{mol} / \mathrm{g}$; mean $\pm \mathrm{SD}$ ) was significantly higher (i.e., $p<.001$ ) than that of concentrates $(70 \pm 39 \mu \mathrm{mol} / \mathrm{ml})$, which in turn was higher $(p<.05)$ than that of mixed drinks $(13 \pm 5 \mu \mathrm{mol} / \mathrm{ml})$ or bulk juices $(18 \pm 11 \mu \mathrm{mol} / \mathrm{ml})$. However, regardless of the type of product, there was considerable variability in $\mathrm{NO}_{3}{ }^{-}$concentration/content between products and often even between samples of the same product. Specifically, there was almost a 50-fold range in $\mathrm{NO}_{3}{ }^{-}$content between different products (albeit partially driven by the assumed $500 \mathrm{ml}$ serving size for bulk juices), whereas the coefficient of variation for the $\mathrm{NO}_{3}{ }^{-}$concentration or content of samples of the same product averaged $30 \% \pm 26 \%$ (range 2-83\%).

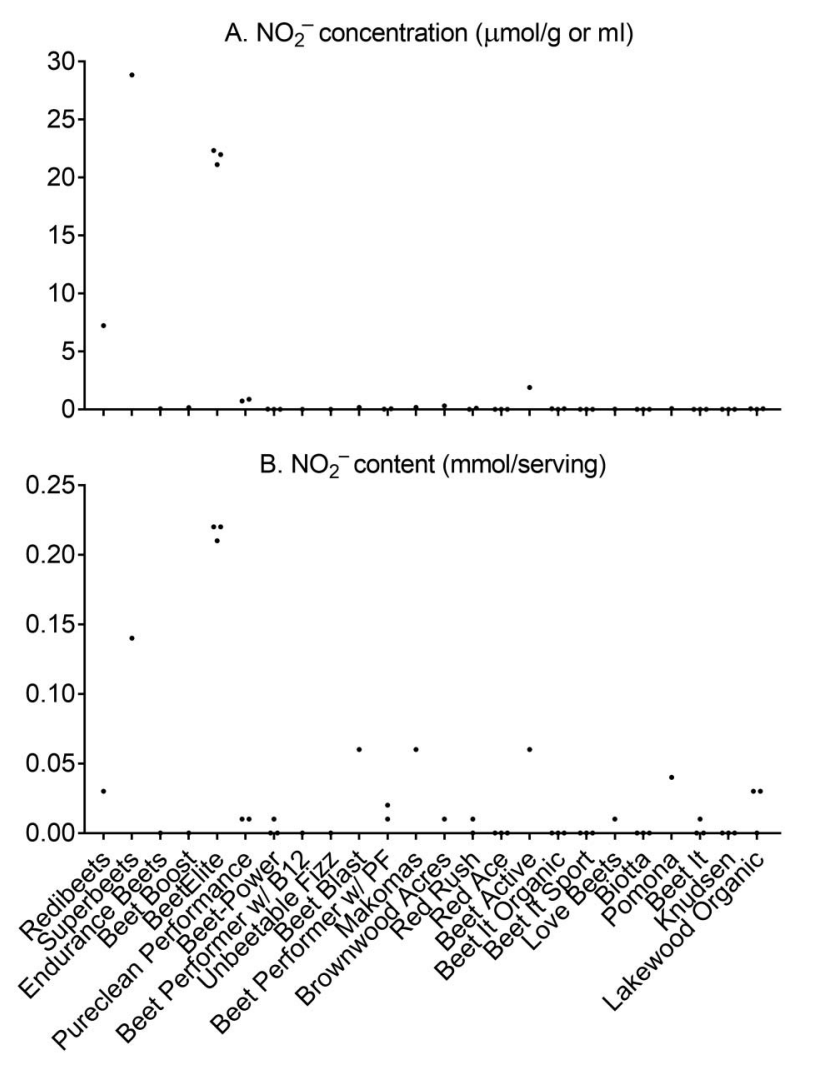

Figure $2-\mathrm{NO}_{2}^{-}$concentration (a) and content (b) of BRJ supplements. Data for each sample tested are shown (circles). $\mathrm{NO}_{2}{ }^{-}=$ nitrite; $\mathrm{BRJ}=$ beetroot juice. 
Table 1 BRJ Products Tested

\begin{tabular}{|c|c|c|c|c|c|}
\hline Company & Product & $\begin{array}{l}\text { Serving } \\
\text { size }\end{array}$ & $\begin{array}{c}\text { Claimed } \mathrm{NO}_{3}^{-} \\
\text {content } \\
\text { (mmol/serving) }\end{array}$ & $\begin{array}{c}\text { Measured } \mathrm{NO}_{3}^{-} \\
\text {content } \\
\text { (mmol/serving) }\end{array}$ & $\begin{array}{c}\text { Measured } \mathrm{NO}_{2}^{-} \\
\text {content } \\
\text { (mmol/serving) }\end{array}$ \\
\hline Powders & & (g) & & & \\
\hline AIM International & RediBeets & 4 & - & 0.43 & 0.03 \\
\hline HumanN & Superbeets & 5 & - & 1.03 & 0.14 \\
\hline HealthySkoop & Endurance Beets & 11 & - & 1.08 & 0.00 \\
\hline Nutrigardens & BeetBoost & 11 & - & 1.78 & 0.00 \\
\hline HumanN & BeetElite & 10 & - & $2.16 \pm 0.28$ & $0.22 \pm 0.01$ \\
\hline PureClean & PureClean Powder & 10 & - & $2.56 \pm 0.32$ & $0.00 \pm 0.00$ \\
\hline Mixed drinks & & $(\mathrm{ml})$ & & & \\
\hline $\mathrm{H} 2 \mathrm{Bev}$ & Beet-Power & 250 & - & $1.02 \pm 0.62$ & $0.00 \pm 0.00$ \\
\hline CAJ Foods & Beet Performer w/ B12 & 250 & - & 3.01 & 0.00 \\
\hline Unbeetable & Unbeetable Fizz & 250 & 4.08 & 3.52 & 0.00 \\
\hline BluePrint Organic & Beet Blast & 355 & - & 3.96 & 0.06 \\
\hline CAJ Foods & Beet Performer w/Passion Fruit & 250 & - & $3.97 \pm 1.47$ & $0.02 \pm 0.01$ \\
\hline Makomas & Ginger Beet Juice & 355 & - & 6.67 & 0.06 \\
\hline Concentrates & & $(\mathrm{ml})$ & & & \\
\hline Brownwood Acres & (beet juice concentrate) & 30 & - & 1.05 & 0.01 \\
\hline AIM International & Red Rush & 74 & 8.06 & $2.39 \pm 1.97$ & $0.01 \pm 0.01$ \\
\hline Red Ace Organics & Beet Performance Supplement & 60 & - & $2.76 \pm 1.54$ & 0.00 \\
\hline CherryActive & BeetActive & 30 & 3.69 & 3.93 & 0.06 \\
\hline James White Drinks & Beet It Organic Beetroot Shot & 70 & 4.84 & $5.93 \pm 0.45$ & $0.00 \pm 0.00$ \\
\hline James White Drinks & Beet It Sport Pro-Elite Shot & 70 & 6.45 & $6.41 \pm 0.60$ & $0.00 \pm 0.00$ \\
\hline Bulk beet juice & & $(\mathrm{ml})$ & & & \\
\hline Love Beets & (beet juice) & $500^{\mathrm{a}}$ & - & 3.35 & 0.01 \\
\hline CAJ Foods & Biotta beet juice & $500^{\mathrm{a}}$ & - & $4.81 \pm 2.16$ & $0.00 \pm 0.00$ \\
\hline Pomona Organic & (beet juice) & $500^{\mathrm{a}}$ & - & 7.11 & 0.04 \\
\hline James White Drinks & Beet It beet juice & $500^{\mathrm{a}}$ & - & $7.55 \pm 1.61$ & $0.00 \pm 0.00$ \\
\hline Knudsen and Sons & (beet juice) & $500^{\mathrm{a}}$ & - & $12.54 \pm 0.25$ & $0.00 \pm 0.00$ \\
\hline Lakewood Organic & (beet juice) & $500^{\mathrm{a}}$ & - & $18.77 \pm 1.59$ & $0.02 \pm 0.02$ \\
\hline
\end{tabular}

Note. $\mathrm{BRJ}=$ beetroot juice; $\mathrm{NO}_{3}^{-}=$nitrate; $\mathrm{NO}_{2}{ }^{-}=$nitrite.

${ }^{\mathrm{a}}$ Assumed serving size.

Although traces of $\mathrm{NO}_{2}^{-}$were detectable in all products, the content was generally very low (i.e., $\leq 0.06 \mathrm{mmol} / \mathrm{serving}$ ) except for two products (i.e., Superbeets and BeetElite, both from HumanN), which on average contained 0.14 and $0.22 \mathrm{mmol} /$ serving, respectively. The potential significance of the higher $\mathrm{NO}_{2}^{-}$content of the latter two products is considered in the Discussion section.

\section{Discussion}

Based on studies demonstrating that BRJ ingestion can enhance exercise performance (Jones et al., 2018), a large number of BRJbased supplements are now marketed to athletes. The $\mathrm{NO}_{3}{ }^{-}$ concentration of beets, however, varies markedly (dos Santos Baião et al., 2016; Wruss et al., 2015), and few BRJ products have been independently tested to determine their $\mathrm{NO}_{3}{ }^{-}$content. Athletes and/or their support staff must therefore generally rely on claims made by producers to determine whether such supplements contain sufficient $\mathrm{NO}_{3}{ }^{-}$to impact physiological function.

To help fill this knowledge gap, we measured the $\mathrm{NO}_{3}{ }^{-}$(and $\mathrm{NO}_{2}{ }^{-}$) content of a wide variety of BRJ-based products, including powders, mixed drinks, concentrates, and bulk juices. Our data demonstrated that there can be significant variation between products and even between samples of the same product. Furthermore, only five of the products consistently contained more than $\geq 5 \mathrm{mmol}$ of $\mathrm{NO}_{3}{ }^{-}$/serving, which based on previous research seems to be the minimal dose required to enhance exercise performance in most individuals (cf. Jones et al., 2018). These findings are in line with the results of a previous study that included a smaller number of BRJ products sold primarily in Europe (Wruss et al., 2015). Although individuals can always choose to consume larger-than-recommended amounts, potential disadvantages to doing so include increased cost, greater volume to ingest, and higher intake of oxalate. The present data are therefore likely to be highly useful to athletes and their support staff in guiding selection of BRJ supplements containing adequate amounts of $\mathrm{NO}_{3}{ }^{-}$(i.e., $\geq 5 \mathrm{mmol} / \mathrm{serving}$ ). They may also help explain some of the negative and null findings in the scientific literature with respect to the effects of BRJ supplementation on exercise performance (Hoon et al., 2015; Oskarsson \& McGawley, 2018). Indeed, given the possible variation even between samples of the same product, scientists should measure the $\mathrm{NO}_{3}{ }^{-}$content of any BRJ supplement used or at least provide the lot or batch number. 
An important assumption of the present study is that any differing effects in vivo would be solely, or at least primarily, due to differences in the $\mathrm{NO}_{3}{ }^{-}$content of the supplements tested. In fact, beets and therefore BRJ-based products contain numerous other potentially biologically active compounds, including carotenoids, betalains, bioflavonoids, and ascorbic acid (Georgiev et al., 2010; Wruss et al., 2015). Indeed, there is some evidence that BRJ may be more effective than simple $\mathrm{NO}_{3}{ }^{-}$salts at reducing muscle pain after eccentric exercise (Clifford et al., 2017) or in enhancing training-induced improvements in peak oxygen consumption (Thompson et al., 2018). However, Lansley et al. (2011b) demonstrated that supplementation with $\mathrm{NO}_{3}{ }^{-}$-depleted BRJ does not alter metabolism or performance during exercise, indicating that the effects of BRJ are mediated primarily if not exclusively by $\mathrm{NO}_{3}{ }^{-}$. Furthermore, by studying only liquid BRJ products, or BRJ powders likely to be consumed as liquids, we avoided any interpretative difficulties that may have arisen had we compared liquid versus solid supplements (e.g., McDonagh et al., 2018) or included products in which BRJ was not the primary ingredient. Still, it is possible that the in vivo efficacy of the various products that we tested may differ due to differences in factors other than their $\mathrm{NO}_{3}{ }^{-}$content.

Along with $\mathrm{NO}_{3}{ }^{-}$, we also measured the $\mathrm{NO}_{2}{ }^{-}$concentration and hence content of the various BRJ supplements. In general, $\mathrm{NO}_{2}{ }^{-}$levels were quite low except for two products (from the same company) containing $\sim 0.2 \mathrm{mmol} \mathrm{\textrm {NO } _ { 2 }}{ }^{-} /$serving. It is difficult to predict the impact that this higher $\mathrm{NO}_{2}{ }^{-}$content might have on in vivo responses to ingestion of these products. Previous studies of higher doses of $\mathrm{NO}_{2}{ }^{-}$, that is, $\sim 2$ to $\sim 4 \mathrm{mmol}$, provided in the form of sodium salt, have demonstrated improvements in various measures of physical function in older individuals (Justice et al., 2015). It is not known, however, whether the smaller amount found in the present products would be sufficient to elicit comparable effects. It might be expected that these two products would have a more rapid onset of action as a result of bypassing the $\mathrm{NO}_{3}{ }^{-}$reduction step of the enterosalivary pathway of NO production. In line with this, McDonagh et al. (2018) recently reported that plasma $\mathrm{NO}_{2}{ }^{-}$ levels peaked within 30 min of ingestion of one of these products (i.e., Superbeets) versus 2-3 hr after ingestion of other BRJ supplements. Unlike the other BRJ products studied, however, Superbeets did not result in a significant reduction in either systolic or mean arterial blood pressure. This is presumably due to the lower dose of $\mathrm{NO}_{3}{ }^{-}$provided (i.e., $\sim 1$ vs. $\sim 6 \mathrm{mmol}$ ), which failed to sustain the initial elevation in $\mathrm{NO}_{2}^{-}$.

In summary, we have measured the $\mathrm{NO}_{3}{ }^{-}$and $\mathrm{NO}_{2}{ }^{-}$concentration and hence content of numerous BRJ supplements. Our data reveal marked variation between different products and often even between different samples of the same product. These data should be beneficial to athletes and/or their support staff interested in implementing BRJ supplementation. They also illustrate the importance of measuring the $\mathrm{NO}_{3}{ }^{-}$content of any BRJ supplements used in scientific research or the putative active ingredient(s) of any nutritional supplement.

\section{Acknowledgments}

E. J. Gallardo was supported by the Diversity Scholars Research Program of the Center for Research and Learning at IUPUI. The publication of this study was made possible by award number R34HL138253 from the National Heart, Lung, and Blood Institute (NHLBI) of the National Institutes of Health (NIH). The contents of this study are solely the responsibility of the authors and do not necessarily represent the official views of the NHLBI or NIH. This study was designed by A. R. Coggan; data were collected and analyzed by E. J. Gallardo and A. R. Coggan; data interpretation and manuscript preparation were performed by A. R. Coggan. Both authors read and approved the final manuscript. The authors have no relevant conflicts of interest.

\section{References}

Bailey, S.J., Fulford, J., Vanhatalo, A., Winyard, P.G., Blackwell, J.R., DiMenna, F.J., . . J Jones, A.M. (2010). Dietary nitrate supplementation enhances muscle contractile efficiency during knee-extensor exercise in humans. Journal of Applied Physiology, 109, 135-148. PubMed ID: 20466802 doi:10.1152/japplphysiol.00046.2010

Bescós, R., Feerrer-Roca, V., Galilea, P.A., Roig, A., Drobnic, F., Sureda, A., ... Pons, A. (2012). Sodium nitrate supplementation does not enhance endurance performance of endurance athletes. Medicine \& Science in Sports \& Exercise, 44, 2400-2409. PubMed ID: 22811030 doi:10.1249/MSS.0b013e3182687e5c

Clifford, T., Howatson, G., West, D.J., \& Stevenson, E.J. (2017). Beetroot juice is more beneficial than sodium nitrate for attenuating muscle pain after strenuous eccentric-bias exercise. Applied Physiology, Nutrition, and Metabolism, 42, 1185-1191. PubMed ID: 28719765 doi:10.1139/apnm-2017-0238

Coggan, A.R., Broadstreet, S.R., Mahmood, K., Mikhalkova, D., Madigan, M., Bole, I., ... Peterson, L.R. (2018a). Dietary nitrate increases $\mathrm{VO}_{2}$ peak and performance but does not alter ventilation or efficiency in patients with heart failure with reduced ejection fraction. Journal of Cardiac Failure, 24, 65-73. PubMed ID: 28916479 doi:10.1016/j.cardfail.2017.09.004

Coggan, A.R., Broadstreet, S.R., Mikhalkova, D., Bole, I., Leibowitz, J.L., Kadkhodayan, A., ... Peterson, L.R. (2018b). Dietary nitrateinduced increases in human muscle power: High versus low responders. Physiological Report, 6, e13575. PubMed ID: 29368802 doi:10. 14814/phy2.13575

Coggan, A.R., Leibowitz, J.L., Anderson Spearie, C., Kadkhodayan, A., Thomas, D.P., Ramamurthy, S., ... Peterson, L.R. (2015a). Acute dietary nitrate intake improves muscle contractile function in patients with heart failure: A double-blind, placebo-controlled, randomized trial. Circulation: Heart Failure, 8, 914-920. PubMed ID: 26179185 doi:10.1161/CIRCHEARTFAILURE.115.002141

Coggan, A.R., Leibowitz, J.L., Kadkhodayan, A., Thomas, D.T., Ramamurthy, S., Spearie, C.A., ... Peterson, L.R. (2015b). Effect of acute dietary nitrate intake on knee extensor speed and power in healthy men and women. Nitric Oxide, 48, 16-21. PubMed ID: 25199856 doi:10.1016/j.niox.2014.08.014

Corleto, K.A., Singh, J., Jayaprakasha, G.K., \& Patil, B.S. (2018). Storage stability of dietary nitrate and phenolic compounds in beetroot (Beta vulgaris) and arugula (Eruca sativa) juices. Journal of Food Science, 83, 1237-1248. PubMed ID: 29660828 doi:10.1111/1750-3841. 14129

dos Santos Baião, D., Conte-Junior, C.A., Paschoalin, V.M.F., \& Alvares, T.S. (2016). Quantitative and comparative contents of nitrate and nitrite in Beta vulgaris L. by reversed-phase high-performance liquid chromatography fluorescence. Food Analytical Methods, 9, 1002 1008.

Georgiev, V.G., Weber, J., Kneschke, E.M., Denev, P.M., Bley, T., \& Pavlov, A.I. (2010). Antioxidant activity and phenolic content of betalain extracts from intact plants and hair root cultures of the red beetroot Beta vulgaris cv. Detroit Dark Red. Plants Foods for Human Nutrition, 65, 105-111. PubMed ID: 20195764 doi:10.1007/s11130010-0156-6 
Hoon, M.W., Fornusek, C., Chapman, P.G., \& Johnson, N.A. (2015). The effect of nitrate supplementation on muscle contraction in healthy adults. European Journal of Sport Science, 8, 712-719. PubMed ID: 26681629 doi:10.1080/17461391.2015.1053418

Jones, A.M., Thompson, C., Wylie, L.J., \& Vanhatalo, A. (2018). Dietary nitrate and physical performance. Annual Review of Nutrition, 38, 303-328. PubMed ID: 30130468 doi:10.1146/annurev-nutr-082117051622

Justice, J.N., Johnson, L.C., DeVan, A.E., Cruickshank-Quinn, C., Reisdorph, N., Bassett, C.J., . . S Seals, D.R. (2015). Improved motor and cognitive performance with sodium nitrite supplementation is related to small metabolite signatures: A pilot trial in middle-aged and older adults. Aging, 7, 1004-1021. PubMed ID: 26626856 doi:10. 18632/aging.100842

Kharti, J., Mills, C.E., Maskell, P., Odongerel, C., \& Webb, A.J. (2017). It is rocket science-Why dietary nitrate is hard to 'beet'! Part I: Twists and turns in the realization of the nitrate-nitrite-NO pathway. British Journal of Clinical Pharmacology, 83, 129-139. PubMed ID: 26896747 doi:10.1111/bcp.12913

Lansley, K.E., Winyard, P.G., Bailey, S.J., Vanhatalo, A., Wilkerson, D.P., Blackwell, J.R., . . . Jones, A.M. (2011a). Acute dietary nitrate supplementation improves cycling time trial performance. Medicine \& Science in Sports \& Exercise, 43, 1125-1131. PubMed ID: 21471821 doi:10.1249/MSS.0b013e31821597b4

Lansley, K.E., Winyard, P.G., Fulford, J., Vanhatalo, A., Bailey, S.J., Blackwell, J.R., ... Jones, A.M. (2011b). Dietary nitrate supplementation reduces the $\mathrm{O}_{2}$ cost of walking and running: A placebocontrolled study. Journal of Applied Physiology, 110, 591-600. PubMed ID: 21071588 doi:10.1152/japplphysiol.01070.2010

McDonagh, S.T.J., Wylie, L.J., Webster, J.M.A., Vanhatalo, A., \& Jones, A.M. (2018). Influence of dietary nitrate food forms on nitrate metabolism and blood pressure in healthy normotensive adults. Nitric
Oxide, 72, 66-74. PubMed ID: 29223585 doi:10.1016/j.niox.2017. 12.001

Oskarsson, J., \& McGawley, K. (2018). No individual or combined effects of caffeine and beetroot-juice supplementation during submaximal or maximal running. Applied Physiology, Nutrition, and Metabolism, 43, 697-703. PubMed ID: 29444414 doi:10.1139/apnm-2017-0547

Rimer, E.G., Peterson, L.R., Coggan, A.R., Martin, J.C. (2016). Increases in maximal cycling power with acute dietary nitrate supplementation. International Journal of Sports Physiology and Performance, 11, 715-720. PubMed ID: 26641379 doi:10.1123/ijspp.2015-0533

Santamaria, P. (2006). Nitrate in vegetables: Toxicity, content, intake and EC regulation. Journal of the Science of Food and Agriculture, 86, 10-17. doi:10.1002/jsfa.2351

Thompson, C., Vanhatalo, A., Kadach, S, Wylie, L.J., Fulford, J., Ferguson, S.K., . . Jones, A.M. (2018). Discrete physiological effects of beetroot juice and potassium nitrate supplementation following 4-wk sprint interval training. Journal of Applied Physiology, 124, 15191528. PubMed ID: 29494294 doi:10.1152/japplphysiol.00047.2018

Troutman, A.D., Gallardo, E.J., Brown, M.B., \& Coggan, A.R. (2018). Measurement of nitrate and nitrite in biopsy-sized muscle samples using HPLC. Journal of Applied Physiology. Advance online publication. doi:10.1152/japplphysiol.00625.2018

Van De Walle, G.P., \& Vukovich, M.D. (2018). The effect of nitrate supplementation on exercise tolerance and performance: A systematic review and meta-analysis. The Journal of Strength and Conditioning Research, 32, 1796-1808. PubMed ID: 29786633 doi:10.1519/JSC. 0000000000002046

Wruss, J., Waldenburger, G., Huemer, S., Uygun, P., Lanzerstorfer, P., Müller, U., ... Weghuber, J. (2015). Composition characteristics of commercial beetroot products and beetroot juice prepared from seven beetroot varieties grown in Upper Austria. Journal of Food Composition and Analysis, 42, 46-55. 